\title{
Near miss maternal mortality, who is responsible? Administration, healthcare system or the people themselves
}

\author{
Smita Tyagi* \\ Department of Obstetrics and Gynecology, Muzaffarnagar Medical College, Muzaffarnagar, Uttar Pradesh, India \\ Received: 21 August 2017 \\ Accepted: 11 September 2017 \\ *Correspondence: \\ Dr. Smita Tyagi, \\ E-mail: drsmitatyagi58@gmail.com \\ Copyright: () the author(s), publisher and licensee Medip Academy. This is an open-access article distributed under \\ the terms of the Creative Commons Attribution Non-Commercial License, which permits unrestricted non-commercial \\ use, distribution, and reproduction in any medium, provided the original work is properly cited.
}

\begin{abstract}
Background: The concept of maternal near miss is assumed to be a better indicator than maternal mortality alone for designing, monitoring, follow up and evaluation of safe motherhood programmes. Objective of present study was to find out the causes of near miss maternal mortality according to WHO and to prevent it.

Methods: It is a prospective study of one year. Cases of maternal near miss were diagnosed and treated according to WHO definitions, which included severe maternal complications, life threatening conditions and critical interventions.

Results: In present study hemorrhage (53\%) was the leading cause of maternal near miss followed by hypertension $(26 \%)$ rupture uterus $(13 \%)$ and obstructed labour (6.6\%). Anemia is the major contributory factor (93\%) of near miss in present study.

Conclusions: To reduce near miss cases there should be major policy changes at the administrative level, it should be well implemental at the health care level and last but not the least people should be made aware of these schemes specialty by TV. Internet and smart phones in this high tech $21^{\text {st }}$ century.
\end{abstract}

Keywords: Critical interventions, Life threatening conditions, Near miss maternal mortality, Severe maternal complications

\section{INTRODUCTION}

The concept of maternal near miss is assumed to be a better indicator than maternal mortality alone for designing, monitoring, follow up and evaluation of safe motherhood programmes. ${ }^{1-3}$

According to WHO, National near miss refers to a woman who nearly died but survived a complication that occurred during pregnancy, child birth or within 42 days of termination of pregnancy. ${ }^{4}$

To implement the maternal near miss approach, WHO has done extensive research and provided essential operational definitions. ${ }^{4}$ They are severe maternal complications, life threatening conditions and critical interventions.

Severe maternal complications include diseases that threaten a woman's life during pregnancy and labour and after termination of pregnancy. A summary list of these conditions has been produced by the WHO working group on maternal deaths and morbidity classifications. ${ }^{5}$ they are severe post partum haemorrhage, severe preeclampsia, eclampsia, sepsis/severe systemic, infection, rupture uterus and contributory/associated conditions. ${ }^{6}$

Life threatening conditions (organ dysfunction) include cardiovascular dysfunction, respiratory dysfunction, renel 
dysfunction, coagulation/haematological dystuction, hepatic dysfunction, neurological dysfunction and uterine dysfunction. ${ }^{4}$ On the same women several life-threatening conditions may be present and if helps to Identify the pattern of intensive support needed by women with severe complications arriving at the health care facility. Critical interventions. ${ }^{4}$ are those that are required in the management of life threatening conditions. Blood transfusion, interventional radiology and laparotomy (including hysterectomy and other emergency surgical interventions in the abdominal cavity, but excluding caesarean section) falls into this category and admission to intensive care unit.

Thus, near miss maternal mortality is a measure of health care system of that country. When a patient of near miss maternal mortality is admitted in the hospital all the medical and para- medical staff of the hospital inducing the senior doctors become alert at the highest level and all the efforts are made to save the patient to prevent mortality. In these cases, we have very little time between life and death so the hospital staff comes in the mode of red alert and even the doctors are in very stressful conditions and in the long run even doctors suffer from hypertension, diabetes and ischemic heart disease. So, every effort should be made to find out the cause of these near miss cases and to prevent it.

\section{METHODS}

It is a prospective study done in Muzaffarnagar Medical College for one year, from January 2016 to December 2017.

All the patients with severe maternal complications and life threatening conditions were identified and critical interventions were made in quick and aggressive manner after putting the department of Obstetrics and Gynaecology in high alert and involving all the senior medical and para medical staff. History was taken regarding the socioeconomic status, education, Antenatal care, mode of transport. Complete general and Obstetrics examination was done and treatment was started very quickly and in aggressive manner to prevent mortality as we have very little time between life and death. So, all efforts were made to prevent mortality.

Most of the patients of severe PPH were home delivery and they came in shock. They all were admitted in ICU. Immediate resuscitative measures were done, all the investigations were sent, blood was arranged and most of them have to put-on vasoactive drugs.

Patients of severe preeclampsia and eclampsia were examined, liver function test, kidney function test and coagulation profile was sent and pregnancy was terminated. Postoperative or post delivery, monitored for cardiovascular, coagulation, respiratory and neurological dysfunction and intensive treatment was given. All the cases of rupture uterus and obstructed labour were immediately sent to O.T., simultaneously all the investigations were sent and blood was arranged. Senior doctor was called in O.T., and suturing of incision or caesarean hysterectomy was done.

\section{RESULTS}

2199 deliveries were conducted in one year, out of which 60 were near miss cases. This comes out to be the incidence of $2.7 \%$. All the patients were of poor socioeconomic status, unbooked, illiterate and of rural areas. All the patients had delay of at least 6-12 hours in reaching the hospital, firstly because their relatives were unable to recognise the alarming signs and symptoms and then there was delay in arranging the transport due to poor financial status. So, the Golden period of early 1-2 hours were lost which can save the patients.

Table 1: Distribution of cases according to maternal age.

\begin{tabular}{|lll|}
\hline Age & No. of cases & $\%$ \\
\hline$<20$ years & 4 & 6.6 \\
\hline 21-30 years & 44 & 73 \\
\hline 31-40 years & 12 & 20 \\
\hline Total & 60 & \\
\hline
\end{tabular}

Maximum no. of cases $(73 \%)$ were in the age group of 21-30 years.

Table 2: Distribution of cases according to parity or gravidity as present study included both Antenatal and postnatal cases.

\begin{tabular}{|lll|}
\hline Parity or gravidity & No. of cases & $\%$ \\
\hline Primi & 12 & 20 \\
\hline $2^{\text {nd }}$ and $3^{\text {rd }}$ & 20 & 33 \\
\hline $4^{\text {th }}$ and more & 28 & 46 \\
\hline Total & 60 & \\
\hline
\end{tabular}

Maximum no. of cases $(46 \%)$ were of $4^{\text {th }}$ para or more. These patients are more prone to maternal near miss.

Table 3: Distribution of cases according to delivery status.

\begin{tabular}{|lll|}
\hline Delivery status & No. of cases & $\%$ \\
\hline Antenatal & 48 & 80 \\
\hline Post Natal & 8 & 13 \\
\hline Abortion & 4 & 66 \\
\hline Total & 60 & \\
\hline
\end{tabular}

Maximum no. (80\%) were antenatal cases, followed by postnatal and abortion cases.

Most of the patients had 2-3 severe maternal complications so it is very difficult to prevent maternal mortality. Anemia was major contributory factor and was present in $93 \%$ of cases. 
Table 4: Distribution of cases according to severe maternal complications as defined by WHO.

\begin{tabular}{|lll|}
\hline Severe maternal complications & $\begin{array}{l}\text { No. of } \\
\text { cases }\end{array}$ & $\%$ \\
\hline Severe PPH & 32 & 53 \\
\hline Sever preeclampsia & 4 & 6.6 \\
\hline Eclampsia & 12 & 20 \\
\hline Sepsis/severe systemic infections & 4 & 6.6 \\
\hline $\begin{array}{l}\text { Rupture uterus } \\
\text { Contributory conditions }\end{array}$ & 8 & 13 \\
\hline Anemia & 56 & 93 \\
\hline $\begin{array}{l}\text { Previous 2 LSCS with placenta } \\
\text { percreta }\end{array}$ & 4 & 6.6 \\
\hline \begin{tabular}{l} 
Obstructed labour \\
\hline
\end{tabular} & 4 & 6.6 \\
\hline
\end{tabular}

Total no. of patients is 60 . There is overlapping of cases as single patient has 2-3 severe maternal complications.

Anemia with severe preeclampsia and eclampsia (26.6\%) was present in most of the Antenatal patients and most of them ended up in DIC and PPH $(32 \%)$. So, this triple severe maternal outcome in some patients was most difficult to treat.

Table 5: Distribution of cases according to life threatening conditions as defined by WHO.

\begin{tabular}{|lll|}
\hline Life threatening conditions & No. of cases & $\%$ \\
\hline Cardiovascular dysfunction & 32 & 53 \\
\hline Coagulation dysfunction & 4 & 6.6 \\
\hline Respiratory dysfunction & 12 & 20 \\
\hline Neurological dysfunction & 4 & 6.6 \\
\hline Hepatic dysfunction & 3 & 5 \\
\hline Uterine dysfunction & 12 & 20 \\
\hline $\begin{array}{l}\text { Laparotomy with suturing of } \\
\text { incision }\end{array}$ & 8 & 13 \\
\hline Caesarean hysterectomy & 4 & 6.6 \\
\hline
\end{tabular}

Total no. of patients are 60 out of 2199 deliveries. There is overlapping of cases as single patient had 2-3 life threatening conditions.

Other combined severe maternal complications were home delivery with severe PPH (32\%) with sepsis (4\%). In most of these patients there was delay in arranging the transport and all of them were in a state of shock when they reached the hospital.

Rupture uterus (13\%) was another severe maternal complication. Most of these patients were previous 2 LSCS with full term pregnancy and they came in labour with rupture uterus.

On history taking it was found either they were not counselled or they were misleaded by dias that they can be delivered vaginally.

Some of the less frequent cases $(6.6 \%)$ were previous 2 LSCS with placenta percreta involving the bladder and $(6.6 \%)$ cases were of obstructed labour from remote rural areas and last but not the least were the cases of medical abortion who took medical abortion drugs directly from medical stores, had severe bleeding at home and were admitted with haemorrhagic shock.

Table 6: Distribution of cases according to critical intervention as defined by WHO.

\begin{tabular}{|lll|}
\hline Critical intervention & No. of cases & $\%$ \\
\hline Blood transfusion & 40 & 66 \\
\hline $\begin{array}{l}\text { Laprotomy and caesarean } \\
\text { hysterectomy }\end{array}$ & 12 & 20 \\
\hline Admission to intensive care unit & 60 & 100
\end{tabular}

Most common was cardiovascular dysfunction (53\%) followed by respiratory dysfunction $(20 \%)$ and uterine dysfunction $(20 \%)$.

Total number of patients are 60 . All the patients (100\%) were admitted to intensive care unit. $66 \%$ had blood transfusion and $20 \%$ had laparotomy.

\section{DISCUSSION}

In present study, there were 2199 births in one year. In present study prevalence of near miss according to severe maternal outcome is $5.6 \%$, according to life threatening conditions is $3.5 \%$ and according to critical intervention is $5 \%$.

According to systematic review published in 2004 Say L et al, prevalence of near miss is $0.80-8.23 \%$ according to severe maternal outcome, $0.38-1.09 \%$ according to life threatening criteria and $0.01-2.99 \%$ according to critical intervention. ${ }^{7}$ Our prevalence is more according to life threatening conditions and critical intervention because ours is a rural based study in developing country according to SM.C.

In present study haemorrhage is the leading cause of near miss $(53 \%)$ followed by hypertension (26\%), rupture uterus $(13 \%)$ and obstructed labour (6.6\%). Anemia was the major contributory factor $(93 \%)$ of near miss in present study. It also suggests that causes of near miss are similar to causes of maternal deaths prevailing in that area.

A study by Khan KS et al also reported that Haemorrhage was the leading cause of maternal death, in Africa (33.9\%) and Asia (30.8\%). ${ }^{8}$ Thus it is in accordance with present study as they are both from developing countries. Anemia was also reported to be an important cause and contributory factor to maternal mortality and severe maternal morbidity by Rajaram P, et al in $1995 .{ }^{9}$

A study by Halder A et al in 2014 also evaluated organ dysfunctions according to WHO near miss criteria and reported that cardiovascular and respiratory dysfunctions were the most frequently seen organ dysfunctions. ${ }^{10}$ 
Cardiovascular dysfunction was present in $53.73 \%$, respiratory dysfunction was present in $60.19 \%$, coagulation dysfunction in the form of failure to form clot in $36.31 \%$ and uterine dysfunction in $32 \%$ of cases. In present study, also cardiovascular $(53 \%)$ was most frequent followed by respiratory dysfunction (20\%) and uterine dysfunction $(20 \%)$.

A WHO multicountry survey (WHOMCS) on maternal and new born health was conducted across 29 countries in Asia, Africa and latin America among 357 centers and showed that older, less educated, and high parity mothers with caesarean deliveries were more likely to have severe maternal outcome. ${ }^{11}$

Postpartum haemorrhage and hypertensive disorders of pregnancy were the most common obstetric complications and cardiovascular, respiratory and coagulation dysfunction were the most common organ dysfunctions in this study. This is in accordance with present study as both are developing and poor countries with limited financial resources and limited skilled paramedical and medical staff. This study was limited by its retrospective design but ours is a prospective study were every patient was admitted in our presence, detailed history was taken from relatives, detailed examination and investigations were done and treatment was started very quickly in our presence, and we were very much satisfied when patient was fully recovered and discharged from the hospital after proper counselling to prevent these near miss cases in future.

All the cases in present study were of low socioeconomic status, rural and unbooked cases. A study by Tuncalp $\mathrm{O}$ et al in 2012 also observed similar results. ${ }^{12}$

\section{CONCLUSION}

To reduce near miss maternal mortality, measures are to be taken at three levels.

Govt. administration who makes the policy, health care system who are responsible for its implementation and last but not least are the people and patients themselves who should be educated enough to know the importance of these health schemes and should take benefit from them. Any lacuna at any level will be step backward in increasing the near miss maternal mortality.

In India, there has been a policy change with promotion of institutional births by skilled birth attendants and provision of emergency obstetric care.

The Janani Suraksha Yojna (JSY) a cash incentive scheme has been initiated to promote institutional deliveries. But increase in load on the health facilities may compromise the quality of care due to limited financial resources and trained skilled medical and paramedical staff. This has to be taken care of by the policy makers and last but not the least, patient and his relatives should be made aware of the health programmes, specially in rural areas by TV and newspapers and in this high tech society internet, smartphones and mobile health care facilities can be used to identify and transfer the patients of maternal near miss mortality to higher centres to prevent, mortality.

\section{Funding: No funding sources}

Conflict of interest: None declared

Ethical approval: The study was approved by the Institutional Ethics Committee

\section{REFERENCES}

1. Ronsmans C, Fillipe V. Beyond the numbers reviewing maternal deaths and complications to make pregnancy safer, Geneva, Switzerland: world organization: Reviewing severe maternal morbidity: learning from survivors from life threatening complications: 2004:103-24.

2. Pattinson RC, Buchmann E, Mantel G, Schoon M, Rees H. Can enquiries into severe acute maternal morbidity act as a surrogate for maternal death enquiries BJOG. 2003;110:889-93.

3. Filippi V, Brugha R, Browen E, Gohou V, Bacci A, De Brouwere V. Obstetric audit in resourse-poor settings: Lessons from a multi-country projest auditing near miss obstetrical. Health Policy Plan. 2004 Jan;19(1):57-66.

4. Evaluating the quality of care for severe pregnancy complication. WHO near miss approach for maternal health: journals. Plos.Org>Plosone>article>. 2011. Available

at http://apps.who.int/iris/bitstream/10665/44692/1/978 9241502221_eng.pdf

5. Say L. WHO working group on maternal mortality and morbidity classifications. Maternal near miss forwards a standard tool for monitoring quality of maternal health care. Best Pract Res Clin Obstet Gynecol. 2009,23:287-296.

6. Report on the world health organization working group on the classification of maternal deaths and severe maternal morbidities. Geneva, world health organization.

7. Say L, Pattinson RC, Gülmezoglu AM. WHO systematic review of maternal morbidity and mortality: the prevalence of severe acute maternal morbidity (near miss). Reproductive Health. 2004 Aug 17;1(1):3.

8. Khan KS, Wojdyla D, Say L, Gülmezoglu AM, Van Look PF. WHO analysis of causes of maternal death: a systematic review. Lancet. 2006;367(9516):106674.

9. Rajaram P, Agrawal A, Swain S, Determinants of maternal mortality. A hospital based study from south india. Indian J Matern Child Health. 1995;6:710.

10. Halder A, Jose R, Vijayselvi R. Maternal mortality and derivations from the WHO near-miss tool: An 
institutional experience over a decade in Southern India. J Turk Ger Gynecol Assoc. 2014;15(4):222-7.

11. Souza JP, Gulmezoglu AM, Vogel J, Carroli G, Lumbiganon P, Ourseshiz. Moving beyond essential interventions for reduction of maternal mortality. (the WHO multi country survey on maternal and new born health): a cross sectional study. Lancet. 2013;381:1747-55.
12. Tuncalp O, Hindin MJ, Souza JP, Chou D, Say L. The prevalence of maternal near miss: A systematic review. BJOG. 2012;119:653-61.

Cite this article as: Tyagi $\mathrm{S}$. Near miss maternal mortality, who is responsible? Administration, healthcare system or the people themselves. Int $\mathbf{J}$ Reprod Contracept Obstet Gynecol 2017;6:4318-22. 